\title{
Effectors: Key Players in Plant-Pathogen Interaction
}

\author{
Rohini M. Kolekar* \\ Department of Plant Biotechnology, Vidya Pratishthan College of Agricultural Biotechnology, \\ Baramati- 413 133, Dist: Pune (MS), India \\ *Corresponding author
}

A B S T R A C T

\begin{tabular}{|l|}
\hline K e y w o r d s \\
Effectors, Effector- \\
triggered immunity, \\
$\begin{array}{l}\text { Pathogen associated } \\
\text { molecular patterns, RNA } \\
\text { silencing, Avirulence }\end{array}$ \\
\hline Article Info \\
\hline $\begin{array}{l}\text { Accepted: } \\
\text { 24 February } 2018 \\
\text { Available Online: } \\
\text { 10 March 2018 }\end{array}$ \\
\hline \hline
\end{tabular}

Plants are exposed to various types of pathogens and pests throughout their life including viruses, bacteria, fungi, oomycetes, nematodes and insects. Plants have evolved for different strategies to combat pathogen entry and disease development. Pathogenic microorganisms have their own strategies to overcome plant defense responses. Pathogens secrete 'effector' molecules which manipulate host cell structure and function to facilitate successful infection and also trigger defense responses in host cells. New emerging concept of 'effector' has been put forth in this review. In addition to our knowledge about plant-pathogen interaction, effector biology opens a sight at molecular level which can help to improve and/or protect our crop plants in future.

\section{Introduction}

Plants constantly come into contact with a diverse range of microorganisms including pathogens. Plants have evolved for different strategies to inhibit pathogen entry and disease development. Microbes, however, have developed their own strategies to counteract with plant defense responses. Plant pathogens, including bacteria, fungi, oomycetes and nematodes secrete effectors proteins that promote successful infection. Pathogen 'effectors' are molecules that manipulate host cell structure and function, thereby facilitating infection (virulence factors or toxins) and/or triggering defense responses (avirulence factors or elicitors) (Kamoun, 2006).

Most of the times, pathogenic microbes enter host cells through natural openings (eg. stomata) or wound sites. As an immediate response to the pathogen attack, plant cell receptors activate resistance mechanism, mediated by pathogen associated molecular patterns (PAMPs) or cell wall-degrading enzymes (CWDEs) which results into compatible or incompatible interaction. As a response to these interactions, several protein molecules will be induced such as resistance (R) proteins, defense-related proteins and biotic stress-responsive proteins etc. Plants 
defend pathogenic attack by means of two basal level of resistance. At first level, nonhost resistance mediates through elicitor molecules which are conserved for a large group of pathogenic microbes. These elicitors are referred to as pathogen associated molecular patterns (PAMPs) e.g. bacterial flagellin and fungal chitin. PAMP recognition by pattern recognition receptors (PRRs) leads to PAMP-triggered immunity (PTI). Pathogenic microbes produce effector proteins which suppress PTI, therefore termed as effector-triggered susceptibility (ETS). At the second level of defense, plant resistance proteins recognize pathogen effectors, which is referred to as effector-triggered immunity (ETI) and results into hypersensitive response (HR) (Flor, 1971). Different effector molecules like cell wall degrading enzymes (CWDEs), toxins, elicitins and PAMPs not only suppress PTI but also manipulate host cell structure and function to spread the disease. Effectors from diverse plant pathogens (bacteria, fungi, oomycetes and nematodes) have been studied. Many changes occur due to interaction between effector and their target molecules in host cells.

Effector molecules will be delivered to their target site into the host cell with the help of structural components of pathogens. In case of bacterial cells, it develops 'injectisomes' or 'Hrp pilus', which creates channel across the plant cell wall and the plasma membrane in bacterial type III and type IV secretion systems. Through these injectisomes, secreted effector molecules will be translocated into the host cell. Bacterial effectors alter transcription process in plant cell during infection. Pseudomonas syringae T3SE HopZ1a effector targets with jasmonate ZIMdomain (JAZ) proteins, transcription repressors of jasmonate (JA)-responsive genes (Jiang et al., 2013). It down regulates host defense mechanism and prevents establishment of cell wall defenses.
Pseudomonas syringae type III effector HopM1 suppresses callose deposition during infection in Arabidopsis thaliana (Gangadharan et al., 2013) and interferes with the recognition event/s that trigger hypersensitivity responses and suppress programmed cell death. Teper et al., (2015) observed that several Xanthomonas type III effectors inhibit cell death mediated by MAPK cascades in Nicotiana benthamiana. Bacterial effectors also manipulate plant hormone signaling (Chen et al., 2017).

During fungal infection, effectors molecules will be delivered to the host cell through a specialized structure 'haustorium', which is surrounded by the extrahaustorial membrane and separated from the host plasma membrane. Fungal effectors are involved in the activities like: host cell wall degradation, Macrophomina phaseolina secretes oxidases, peroxidases, and hydrolytic enzymes for degrading cell wall polysaccharides and lignocelluloses to penetrate into the host tissue (Islam et al., 2012); inhibition of host defensive enzymes such as Kunitz-type cysteine protease inhibitor of Arabidopsis thaliana (Rustgi et al., 2018) and suppression of plant cell death responses induced by toxic proteins (Wang and Huang, 2011). Secreted LysM Protein1 (Slp1) effector of rice blast fungus Magnaporthe oryzae, accumulates at the interface between the fungal cell wall and the rice plasma membrane, can bind to chitin, and suppress chitin-induced plant immune responses, including generation of reactive oxygen species and plant defense gene expression (Mentlak et al., 2012).

Oomycetes effectors are categorized into two groups based on their target sites, extracellular and intracellular. Extracellular effectors are active in the apoplastic space and interact with extracellular host molecules whereas cytoplasmic effectors play their function inside the host cell cytoplasm. 
Secretion and translocation of cytoplasmic effectors are mediated by haustoria. In general, like fungal effectors, oomycetes effectors secrets cell wall degrading enzymes (Ah-Fong et al., 2017). Oomycetes effectors also inhibit host's hydrolytic enzymes to protect their own cell walls from degradation. Johnson et al., (2016) reported that, oomycete pathogen, Phytophthora capsici causing foot rot disease, secretes a glucanase inhibitor protein (GIP), which is capable of inhibiting defense proteins like endoglucanases and beta-1,3 glucanse. Apoplastic effectors (small cysteine-rich proteins) are involved in the stabilization of apoplastic proteins. For example, elicitins produced by oomycetes play an important role in oomycete pathogenicity by binding to the plant lipids and act as lipid-transfer proteins (Blein et al., 2002).

There are two broad groups of cytoplasmic oomycete effectors, RXLR and CRN effectors. Conserved oomycete RXLR effectors, which possess an RXLR motif (Arginine-any amino acid-LeucineArginine) near their $N$-terminus, suppress PTI and ETI across diverse plant species (Deb et al., 2018). Crinkler (CRN- for Crinkling and necrosis) effectors have conserved motifs FLAK (Phenylalanine-Leucine-AlanineLysine), which induces cell death by interfering with host's physiological processes (Mafurah et al., 2015).

Interestingly at the time of viral infection, RNA silencing is the primary level of plants defense which regulates accumulation of endogenous and foreign RNA molecules. Double stranded RNA genomes of plant viruses or replication intermediates may trigger host silencing of the entire viral genome, preventing systemic viral spread. Viral virulence determinants which are considered as effectors, interfere with unique components of the host silencing machinery and suppress the host RNA silencing response (Csorba et al., 2015). Simultaneously, plants use a second defense mechanism to recognize and restrict virus movement. Specific $R$ proteins recognize viral components, either silencing suppressors or other proteins that accumulate following successful viral replication and translation (Cosson et al., 2012; Ishibashi and Ishikawa, 2013). Similarly, effector-triggered immune responses against bacteria and fungi also function to restrict viruses. Ability of bacterial and fungal effectors to suppress PAMPtriggered defenses limits the host range of those pathogens. Whereas, virus silencing suppressor is a major factor which determines the host range of that virus. P1/HC-Pro, a viral component of Potyvirus, acts as a suppressor of posttranslational gene silencing. Also, P1/HC-Pro has been shown to transactivate the replication and enhance the pathogenicity of a broad range of heterologous plant virus (Anandalakshmi et al., 1998).

Several nematode effectors are identified in plant-nematode interaction. Nematode effectors are the secreted protein products in the nematode esophageal gland and directed for the secretion into parasitized plant cells and tissues through the stylet, a hollow mouth spear. The root knot nematodes effectors are responsible for giant cell formation and endodermis proliferation of the host cells. Cyst nematode effectors help in the infection and formation of feeding site 'syncytia' through subsequent morphological and physiological changes of host cells. Nematode effectors involve in the plant cell wall modification; assembly and protein modification; interference with cell cycle, plant metabolic activities, signal transduction, transcription activity, post translational modification and hormone responses in host cells; detoxification of reactive oxygen species etc (Shukla et al., 2016; Gillet et al., 
2017). A well-studied example is MjTTL5 effector which is secreted by Meloidogyne javanica nematode. During infection, MjTTL5 effector interacts with the Arabidopsis ferodoxin molecule At FTRc and induces host reactive oxygen speciesscavenging activity. MjTTL5 effector suppresses plant defense mechanism in Arabidopsis and inhibits host resistance to nematodes (Lin et al., 2016).

Plant hormones (Jasmonic acid, salicylic acid and ethylene) and their signaling networks are important for PTI and ETI responses. Many effectors mimic plant molecules which are involved in the regulatory processes of plant hormones (Kazan and Lyons, 2014; Patkar and Nakvi, 2017). Pseudomonas syringae effector protein AvrB regulates plasma membrane proton ATPase which modulates JA signaling for stomatal invasion (Zhou et al., 2015).

Effectors can be expressed transiently or transgenically in planta to determine whether they produce phenotypes, such as enhanced susceptibility to pathogens, or whether they suppress plant innate immunity outputs. TDNA knock-out and RNA interference knock down plants or plants over-expressing effector targets can be used to determine target function. Direct or indirect way, recognition of effector targets will result into the crop improvement.

\section{References}

Ah-Fong, A. M. V., Shrivastava, J. and Judelson, H. S. (2017). Lifestyle, gene gain and loss, and transcriptional remodeling cause divergence in the transcriptomes of Phytophthora infestans and Pythium ultimum during potato tuber colonization. BMC Genomics.18: 764.
Anandalakshmi, R., Pruss, G. J., Ge, X., Marathe, R., Mallory, A. C., Smith, T. H. and Vance, V. B. (1998). A viral suppressor of gene silencing in plants. Proc. Natl. Acad. Sci. 95(22): 1307913084.

Blein, J. P., Coutos-Thévenot, P., Marion, D. and Ponchet, M. (2002). From elicitins to lipid-transfer proteins: a new insight in cell signalling involved in plant defence mechanisms, Trends in Plant Science 7(7):293-296.

Chen, H., Chen, J., Li, M., Chang, M., Xu, K., Shang, Z., Zhao, Y., Palmer, I., Zhang, Y., McGill, J., Alfano, J. R., Nishimura, M. T., Liu, F. and Fu, Z. Q. (2017). A bacterial type III effector targets the master regulator of salicylic acid signaling, NPR1, to subvert plant immunity Cell Host and Microbe. 22(6):777-788.

Cosson, P., Schurdi-Levraud, V., Le, Q. H., Sicard, O., Caballero, M., Roux, F., Gall, O. L. Candresse, T., Revers, F. (2012).The RTM resistance to potyviruses in Arabidopsis thaliana: natural variation of the RTM genes and evidence for the implication of additional genes. PLoS One 7: e39169.

Csorba, T., Kontra, L. and Burgyan, J. (2015). Viral silencing suppressors: Tools forged to fine-tune host-pathogen coexistence. Virology. 479-480, 85103.

Deb, D., Anderson, R. G., How-Yew-Kin, T., Tyler, B. M., McDowell, J. M. (2018). Conserved RxLR effectors from oomycetes hyaloperonospora Arabidopsidis and Phytophthora sojae suppress PAMP- and EffectorTriggered Immunity in diverse plants. Mol. Plant Microbe Interact. 31(3):374385.

Flor, H. H. (1971). Current status of the genefor-gene concept. Annual Reviews in Phytopathology. 9: 275-296. 
Gangadharan, A., Sreerekha, M V., Whitehill, J., Ham, J. H. and Mackey, D. (2013). The Pseudomonas syringae pv. Tomato type III effector HopM1 suppresses Arabidopsis defenses independent of suppressing salicylic acid signaling and of targeting AtMIN7, PloS One. 8 (12):e82032

Gillet, F. X., Bournaud, C., De Souza Júnior, J. D. A. and Grossi-de-Sa M. F. (2017) Plant-parasitic nematodes: towards understanding molecular players in stress responses. Annals of Botany. 119(5):775-789.

Ishibashi, K. and Ishikawa, M. (2013). The resistance protein Tm-1 inhibits formation of a Tomato Mosaic Virus replication protein-host membrane protein complex. Journal of Virology. 87: 7933-7939.

Islam, M. S.,Haque, M. S., Islam, M. M., Emdad, E. M., Halim, A., Hossen, Q. M. M., Hossain, M. Z., Ahmed, B., Rahim, S., Rahman, M. S., Alam, M. M. Hou, S., Wan, X., Saito, J. A. and Alam, M. (2012). Tools to kill: Genome of one of the most destructive plant pathogenic fungi Macrophomina phaseolina. BMC Genomics.13:493.

Jiang, S., Yao, J., Ma, K. W., Zhou, H., Song, J., He, S.Y. and Ma, W. (2013). Bacterial effector activates Jasmonate signaling by directly targeting JAZ transcriptional repressors. PLoS Pathog. 9:e1003715.

Johnson G., K., Rosana Babu, O., Vijesh Kumar, I. P., Santhosh Eapen, J. and Anandaraj, M. (2016). Interplay of genes in plant-pathogen interactions: In planta expression and docking studies of a beta 1,3 glucanase gene from Piper colubrinum and a glucanase inhibitor gene from Phytophthora capsici. Physiol. Mol. Biol. Plants. 22(4): 567573.
Kamoun, S. (2006). A catalogue of the effector secretome of plant pathogenic oomycetes. Annual Reviews in Phytopathology. 44:41-60.

Kazan, K. and Lyons, R. (2014). Intervention of Phytohormone Pathways by Pathogen Effectors. The Plant Cell. 26: 2285-2309.

Lin, B., Zhuo, K., Chen, S., Hu, L., Sun, L., Wang, X., Zhang, L. H. and Liao, J. (2016). A novel nematode effector suppresses plant immunity by activating host reactive oxygen speciesscavenging system. New Phytologist. 209(3): 1159-1173.

Mafurah, J. J., Ma, H., Zhang, M., Xu, J., He, F., Ye, T., Shen, D., Chen, Y., Rajput, N. A., Dou, D. (2015). A virulence essential CRN effector of Phytophthora capsici suppresses host defense and induces cell death in plant nucleus. PLoS One. 10(5):e0127965.

Mentlak, T. A., Kombrink, A., Shinya, T., Ryder, L. S., Otomo, I., Saitoh, H., Terauchi, R., Nishizawa, Y., Shibuya, N., Thomma, B. P. H. J. and Talbot, N. J. (2012). Effector-Mediated Suppression of chitin-triggered immunity by Magnaporthe oryzae is necessary for rice blast disease, The Plant Cell, 24: 322-335.

Patkar, R. N. and Nakvi, N. I. (2017). Fungal manipulation of hormone-regulated plant defense. PLoS Pathogens. 13(6): e1006334.

Rustgi, S., Boex-Fontvieille, E., Reinbothe, C., von Wettstein, D. and Reinbothe, S. (2018).The complex world of plant protease inhibitors: Insights into a Kunitz-type cysteine protease inhibitor of Arabidopsis thaliana, Communicative and Integrative Biology. 11(1): e1368599.

Shukla N., Kaur, P. and Kumar, A. (2016). Molecular aspects of plant-nematode 
interactions. Indian Journal of Plant Physiology. 21:477-488.

Teper, D., Sunitha, S., Martin, G. B. and Sessa, G. (2015). Five Xanthomonas type III effectors suppress cell death induced by components of immunity associated MAP kinase cascades, Plant Signaling and Behavior. 10(10): e1064573.

Wang and Huang, 2011, Assays for effectormediated suppression of programmed cell death in yeast, Methods Mol Biol. 712:173-180.

Zhou, Z., Wu, Y., Yang, Y., Du, M., Zhang, X., Guo, Y., Li, C., Zhou, J. M. (2015). An Arabidopsis plasma membrane proton ATPase modulates JA signaling and is exploited by the Pseudomonas syringae effector protein $\mathrm{AvrB}$ for stomatal invasion, 27(7):2032-2041.

\section{How to cite this article:}

Rohini M. Kolekar. 2018. Effectors: Key Players in Plant-Pathogen Interaction. Int.J.Curr.Microbiol.App.Sci. 7(03): 2918-2923. doi: https://doi.org/10.20546/ijcmas.2018.703.337 